\title{
Governance of HIV/AIDS: implications for health sector
} response

\author{
Manoj Kar* \\ Abstract \\ This paper reviews the essence of effective governance and importance of a multi-sectoral approach in generating \\ health systems response to HIV/AIDS. This comprehensive approach highlights the importance of integrating \\ reproductive sexual health programs and HIV prevention services, including peer education, life skills, and \\ Voluntary Counseling and Testing (VCT), for Prevention of Mother-to-Child Transmission (PMTCT) and \\ reaching out to People Living with HIV/AIDS (PLHA). \\ Research implications for governance of health systems response to HIV/AIDS, integrated youth health policies \\ and high-level political commitment, are emphasized by strategic implications for HIV/AIDS control and followed \\ by a policy thrust on health systems as a strategic plan to achieve sustainability in the fight against HIV/AIDS. \\ Keywords: Health Policy, Governance, Multi-Sectoral Approach, Health Systems Strengthening, PLHA, Health \\ Systems Research, Social Dterminants and Sustainability \\ Copyright: ( 2014 by Kerman University of Medical Sciences \\ Citation: Kar M. Governance of HIV/AIDS: implications for health sector response. Int J Health Policy Manag \\ 2014; 2: 39-44. doi: 10.15171/ijhpm.2014.07
}

Article History:

Received: 5 November 2013

Accepted: 24 December 2013

ePublished: 7 January 2014

Correspondence to:

Manoj Kar

Email: manojkar.iie10@gmail.com

\section{HIV/AIDS scenario: a different epidemic}

Globally, there were 35.30 million people living with HIV by 2012 with 2.10 million in India (1). Government of India estimates that about 2.40 million Indians are living with HIV (1.93-3.04 million) with an adult prevalence of $0.31 \%$ (2009) of whom $39 \%$ are female and $4.40 \%$ are children (2). India began preventive actions targeting to slow down the epidemic at an early stage; a possible explanation for the low prevalence of $0.30 \%$ in the adult population (3).

During the Cairo International Conference on Population and Development (ICPD+5), all countries recognized the genuine opportunity to plan for the end of AIDS, and accordingly agreed on targets for action. These actions are to be insured through provision of access to information, education, and services necessary to develop life skills required to reduce vulnerability to HIV infection (4).

The case of India: current situation and challenges ahead The primary drivers of HIV epidemic in India are commercial female sex work, unprotected sex between men who have sex with men, and injecting drug use. Based on program data, unprotected sex (87.40\% heterosexual and 1.30\% homosexual) is the major route of HIV transmission, followed by transmission from parent to child (5.40\%) and use of infected blood and blood products (1\%). While injecting drug use is the predominant route of transmission in North Eastern Indian states, it accounts for $1.60 \%$ of HIV infections (Figure 1). HIV epidemic in India is concentrated in nature and heterogeneous in its spread. While interventions have brought successful decline in HIV epidemic at most of the places, emerging pockets and risk groups with high vulnerability warrant focused attention under the program. Challenges remain in sustaining effective governance of health sector response using health systems approach in the existing scenario to fight against AIDS in India.

In a large diversity setting in India, government effort would be difficult and ineffective in strategizing disease-specific safeguards for infection control and health waste management instead, the facilitation of health systems strengthening approach with defined responsibilities at the implementation levels is advocated.

Health systems approach is needed in deciding safeguard policies instead of bureaucratic 'box-ticking' compliance that uses scarce time and disease-specific resources without adding value for intended beneficiaries. In case of HIV/AIDS, convergence strategies with National Rural Health Mission (NRHM) remains strategic as well as challenging using health systems as response. Strengthening health systemsparticularly HIV-related infrastructure, logistics system, and human resource capacities-is inbuilt to the national program of HIV/AIDS instead of being convergent with NRHM which accounts for health systems capacity and outcome in both rural and urban areas.

How do these stresses, relationships, and changes in governments affect health systems' capacities to deliver treatment and care? How are legislative and policy reforms in area of local government, service delivery, and governance impacting the access of HIV/AIDS affected households and communities to health, education, transportation, agricultural extension, and other services? What governance factors do determine differences among countries and regions? What challenges does the availability of treatment create for distribution, access, 


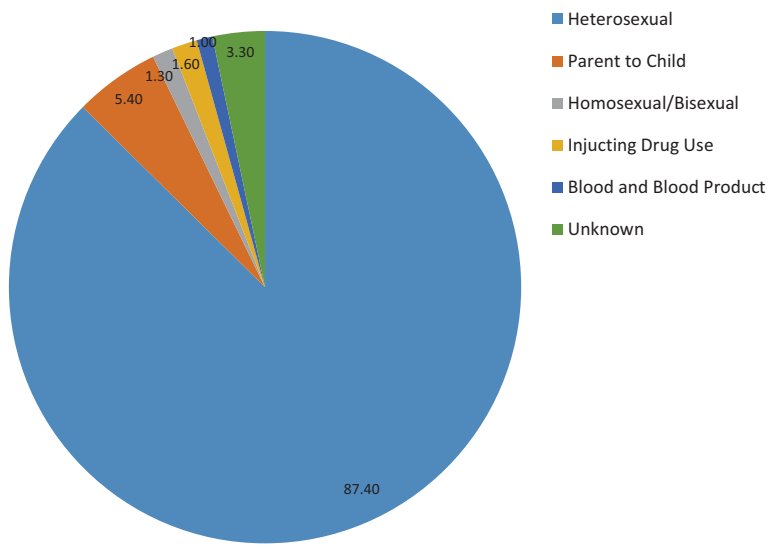

Figure 1. Routes of Transmission of HIV, India, 2010-11

and service provision capacity within the provisioning of health systems strengthening? (Figure 2)

In this regard, how are public policy choices made and with what implications for health security? What drives innovative responses, and conversely, the absence of response, pressure from civil society, international promises of assistance, political leadership in the form of the highest level of political commitment.

Battle against HIV/AIDS lies squarely at intersection between 'emergency response' and 'health development intervention' and this has placed it among the most difficult policy and strategic issues facing national and local governments, and international development community. Confronting the pandemic requires dealing with a set of severe tensions between (1):

- Fast emergency response and sustainable development intervention;

- Centralized and decentralized organization and resource mobilization;

- Authoritarian and coercive measures of control and participatory involvement of grassroots organizations;

- The imperative of public health (the good of the community), health security, respect for individual rights, and community participation;

- Pressures to allocate resources, to immediate killer diseases, and imperative to head off an epidemic whose deadliness is not immediately evident.

This tension-ridden character of fight against HIV/AIDS pandemic places it squarely in the domain of governance, which is all about reconciling tensions and making choices (5). It also requires application of the 'art of governance, since the fight against HIV/AIDS defies easy resolution through development of universally applicable 'templates' for organizational and programatic responses (6). How can governments institutionalize an emergency response? This is part of the problem.

While social scientists have been carrying out significant work on HIV/AIDS (7), there has been very little research on HIV/ AIDS especially in the domain of health systems strengthening research. Figure 3, refers to research domains that differ at their core in the type of research questions they address and their cross-cutting with health system and governance research issues (8). What exists so far has focused on the impact of the epidemic in terms of greater demands placed on government services and the erosion of government capability through AIDS-related deaths (9).

Much of the discussion about government action to date has been limited to descriptive accounts of measures taken and the progress made to achieve targets in surveillance, prevention (especially individual behaviour change), care, and treatment (10). This briefly reflects the government action in these terms in India, within a political analytical framework in order to understand:

- What permitted stronger government action on?

- What choices made a difference to outcomes?

- How important was the shift to a 'multi-sectoral approach' and what is the appropriate role of scientific, medical, and technical action within a multi-sectoral approach in generating an effective health systems response?
SYSTEM BUILDING BLOCK

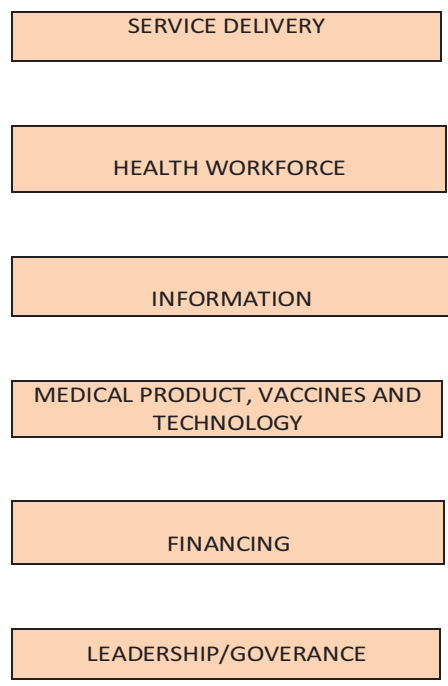

OVERALL GOALS/OUTCOMES

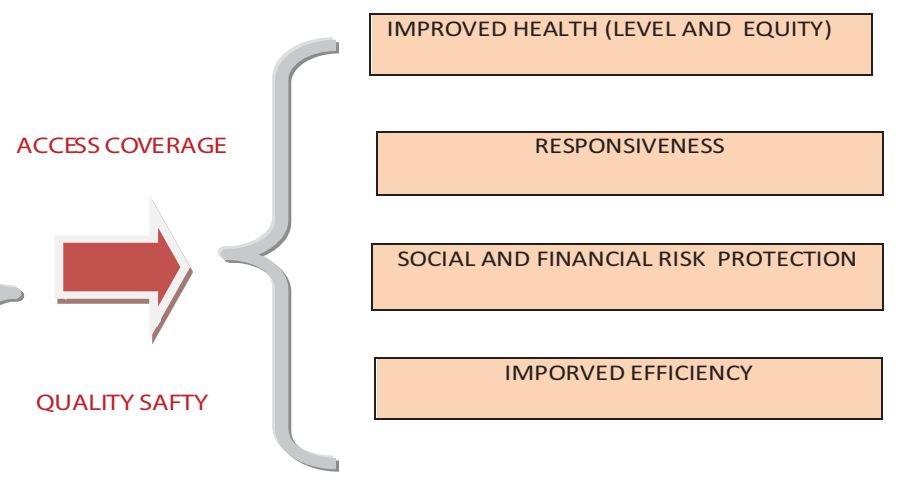

Figure 2. Building blocks of health systems. Adapted from the WHO framework for action on health systems strengthening 


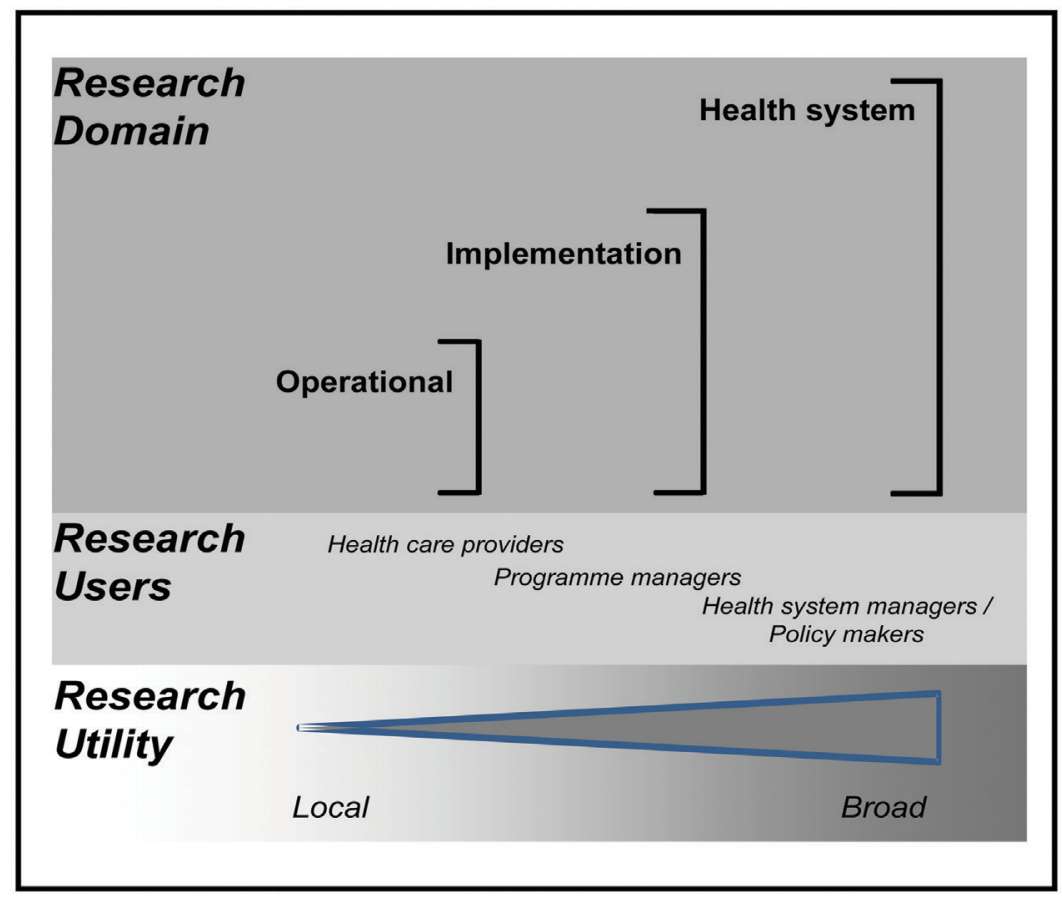

Figure 3. Research to improve health systems response on HIVIAIDS. Adapted from Remme et al. 'Defining Research to Improve Health Systems', published November 16, 2010. DOI: 10.1371/journal.pmed.1001000' (8)

Effective governance-multi-sectoral approach to HIV/AIDS Linkages between HIV and governance are becoming more widely understood and acknowledged. First off all, more developed countries generally have lower prevalence rates. 'As government, by addressing income and economic development aspects of one's lives, one is dealing with the background of HIV vulnerabilities that push individuals to take risks which they reasonably would not have taken if the environment was more favorable for their livelihood'.

Concurrently, countries with good governance appear to have low, stable HIV prevalence rates with stronger health systems. Putting these broad causes and effects together weaves the basic story that developing stronger health systems and good governance will lead to a lower more stable HIV prevalence rate (11). However, it is not only political and policy science, which supplies a strong case for the link between governance and AIDS. From an economic standpoint, market failures in case of HIV/AIDS justify government intervention. Social capital, moreover, will ease the burden on government to provide social welfare and health services. Whiteside argues that having a fair legal system, respect for human rights, and support for the rights and empowerment of women would help reduce the stigma and increases the openness, and AIDS prevention (12). On the other hand, although vertical AIDS programs have resulted in significant progress and have proven that countries are able to design and implement multi-sectoral national responses by taking into account the crucial role of sectors beyond health, they have also highlighted great disparities in health systems and an inefficient and duplicative use of resources. Successful HIV responses combine strong health services with strategic action in other sectors to address the underlying socio-economic factors that influence the epidemic; these include income and gender inequality, access to education, migration patterns, and inadequate protection of human rights (13).
Critical issues on governance of HIV/AIDS

Opportunities and challenges for health sector response: health systems

Governance of HIV/AIDS is critical for healthcare policies and programs in issues of providing stronger health systems. HIV/AIDS remains an unfinished Millennium Development Goals (MDGs), underscoring the need for continued and strengthened approaches and the determination to address the most serious of contemporary health as well as health systems challenges. Governance effectiveness revolves around these features of health systems strengthening which will lay the groundwork to end the AIDS epidemic (Figure 4).

- Decentralization of the healthcare system;

- Integration of services for HIV/AIDS prevention, care, and support within health systems strengthening mechanism;

- Linking reproductive sexual health with HIV/AIDS prevention and care;

- HIV/AIDS health services as part of a multi-sectoral national response in coordination with the social development and education sectors in particular;

- Effectiveness of alliances and partnerships in healthcare delivery within the framework of Health Systems Strengthening (HSS) (WHO).

'Inappropriate negative attitudes must be dispelled. They include the view that nothing can be done, care is a bottomless pit, prevention is the only option, and HIV/AIDS clinical services are not essential'.

The framework consists of six building blocks: service delivery; health workforce; information; medical products, vaccines, and technologies; financing; and leadership and governance. However, these blocks have become synonymous with the health system and HSS, such that any program making improvements in any block in any fashion can be said to do "health system 


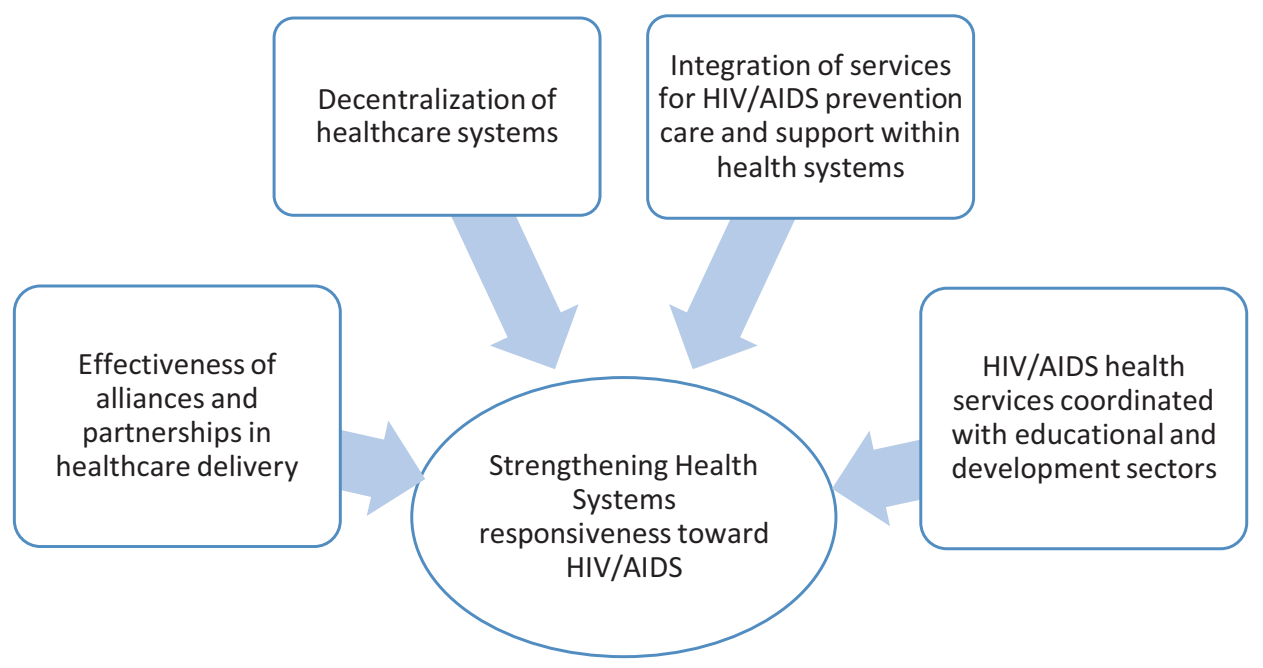

Figure 4. Multi-sectoral HIVIAIDS Strategy within HSS Framework (WHO)

strengthening". This ignores that the definition of HSS also calls for improving the interactions between the building blocks and for sustainable improvements "across health services and health outcomes".

In contrast, strengthening the health system is accomplished by more comprehensive changes to policies and regulations, organizational structures, and relationships across the health system building blocks that motivate changes in behavior, and/ or allow more effective use of resources to improve multiple health services. Both, supporting and strengthening, are important and necessary, and the balance must be driven by the country context.

Not distinguishing supportive activities from strengthening ones will lead to unmet expectations of stronger health systems, as well as the neglect of critical system strengthening activities. Governance of health systems needs addressing these interventions:

- To have cross-cutting benefits beyond a single disease;

- To address policy and organizational constraints or strengthen the relationships between the building blocks;

- To produce permanent systemic impact beyond the term of the project, tailored to country-specific constraints and opportunities, with clearly defined roles for country institutions.

Interpretation of HSS has varied widely however, with much of the focus to date on alleviating input constraints, whereas less attention has been given to other performance drivers. It is important to distinguish activities that support the health system from ones that strengthen the health system. Strengthening the health system is accomplished by more comprehensive changes to performance drivers such as policies and regulations, organizational structures, and relationships across the health system to motivate changes in behavior and/ or allow more effective use of resources to improve multiple health services. This is what is emphasized as the essence of 'governance of health systems' in addressing disease-specific interventions for HIV/AIDS strategies.

\section{Decentralization of health services}

A key aspect of governance reform is decentralization, or the shift of control, planning, and financing (to varying degrees) away from the central ministry of health toward a district level. This separates the policy-making and funding responsibilities of national government from the service delivery responsibilities held by states or districts (14). Decentralization of health services is particularly relevant to HIV/AIDS within the framework of health systems. For example, given the severity and scope of the epidemic, treatment costs are extraordinary; expecting or relying upon sub-national governments to take on that burden without proper provisioning will not work with weak health systems. Further, community-based support initiatives and home-based care are increasingly being promoted to insure continuum of care at the grassroots level.

Decentralization also carries all dynamics and difficulties caused when the principal-central government-has somewhat differing objectives and interests than the local agents to whom they have delegated authority or resources within the capacity of functional health system (15).

Integration of primary healthcare services-health systems Strategic issues surrounding the integration of Primary HealthCare (PHC) services is the question of how and to what extent PHC services should be available to users together, and which PHC interventions are better run as vertical programs. This debate ties into HIV/AIDS because of the suggestion that contraceptive services and family planning-often established vertically run programs-ought to be expanded to include HIV/AIDS prevention, education, condom provision programs, voluntary counseling and testing, and PPTCT (prevention of Parents to Child Transmission) within the implementation framework of functional health systems (NACP, NACO, GOI, 2012-13) (16).

Integration of HIV/AIDS services is especially complicated and contains unique issues $(17,18)$. First, the virus itself weakens immune system, while opportunistic infections-such as TB are the presenting problems and ultimately the source of death. How and why to distinguish the treatment of HIV-enabled or sourced infections is a question. Second, legal rights issues and discrimination surrounding HIV positive persons can lead to isolation or referral of patients when technically this is unnecessary. As a result, many People Living with HIV/AIDS 
(PLHA) are managed at inappropriate levels of care. Third, as yet there is no cure for HIV/AIDS, prevention is linked with care and drug treatment. Fourth, as HIV/AIDS progresses through stages of infection, continuity of care is especially important (19).

\section{Multi-sectoral approach}

Epidemiological and social character of HIV/AIDS epidemic has meant that biomedical responses are entirely insufficient to any attempt to bring it under control and deal with short, medium and long-term impact on social, economic and political considerations for a functional and effective health system (18). Following mentioned factors discuss a number of problems related to the current reigning for governance of national HIV/AIDS strategies:

- A 'multi-sectoral approach' is taken to mean both 'mainstreaming' HIV/AIDS in all government activities, e.g. all departments incorporate an assessment of the impact of the epidemic on their work and design mitigating measures as well as actions to combat the epidemic in their domains, and 'full involvement of non-governmental sectors-religious, voluntary, and private-in planning and implementing HIV/AIDS campaigns. These are two distinct goals which require different measures and they do not necessarily go together.

- There is in the template an implicit assessment of organizations' inability within the state, or public authority, to implement HIV/AIDS programs and an implicit, virtually ideological belief that NGOs, religious organizations, and private sector organizations will be able to do better. India's Community-Based Organization (CBO) strategy under National Aids Control Programme phase-III (NACP III) - a successful example of a multi-sectoral approach using decentralized plans, can effectively engage NGOs at the grassroots level.

- In reaction to over-reliance on weak health systems in the past, the model has tended to secondries medical expertise, by treating ministries of health as just one among many co-equal (bureaucratic and incompetent) government ministries and the medical dimension of fight against the epidemic as just one among many co-equal aspects of what must be a multi-dimensional effort.

- Most importantly, the establishment of supra-ministerial bodies effectively ends up in inadequate attempts to reinvent government and to replace what is essentially a political challenge of prioritizing HIV/AIDS in government and non-government sectors with an organizational fix.

The challenge is to convince and encourage ministries outside health to take on HIV/AIDS as part of their work-to integrate the fight against the disease (19). At this point, structures and systems are needed to push other ministries to take this issue on themselves instead of sitting back and this leadership is provided by Ministry of Health through health systems functioning. India's mainstreaming strategy under NACP III is a successful example for facilitating inter-ministerial coordination. Each of these challenges provides an opportunity for intersectoral actions. They include:

- Counseling and dissemination of basic information;

- Support groups and networks of PLHA;

- Home- and community-based care and support;

- Support for children orphaned by AIDS;
- Improving access to essential drugs;

- Palliative and step-down care;

- Partnerships with NGOs, Civil Society and the private sector;

- Sustainability of mainstreaming effort;

Broad movement toward the establishment of alliances and partnerships in health systems, NGOs, and healthcare delivery is also relevant to HIV/AIDS treatment, care, and prevention. They work in tackling broader social and epidemiological determinants of health and well-being of populations in a sustainable manner, and in promoting individual healthrelated behavior change (19). India's successful experience in NACP III lead to partnerships among local authorities, civil society organizations (NGOs/CBOs), people living with HIV, women's groups, and key population groups to strengthen the implementation of local AIDS responses.

Implications for governance of health systems response to HIV/AIDS

- Limited targeting, low coverage and quality of prevention;

- Low care and treatment access and quality within health systems;

- Limited scope for linkages with public health systems capacity;

- Limited multi-sectoral involvement;

- Weak surveillance and Monitoring and Evaluation (M \& E) systems;

- Limited transparency and weak accountability within health systems;

- Limited considerations for the weak health systems in which the implementation of HIV/AIDS services operate;

- High level of gender inequalities;

- Absence of a framework for enabling involvement of NGOs;

- High level of denial, stigma, and discrimination of PLHA and Limited involvement for community participation.

There can be no quick fixes to this human catastrophe-some forms of which will only manifest over time. The tragic reality is that, HIV/AIDS and its deadly legacy will extend well into future, with or without a vaccine that is affordable and accessible. Thus, short-term need for long-term solutions is now another incumbent priority-governance of effective health systems response for combating HIV/AIDS.

As a roadmap in the provision of people-centred and rightsbased services, effective governance of HIV response has many lessons to share with the emerging challenges of integration with health systems and the development paradigm using social determinants. Eliminating parallel and compartmental systems and usefully integrating programs and services require the below-mentioned strategies to generate sustainable response:

1. Joint budgeting is needed for HIV and other diseases or overall health sectors and health planning should be informed by and linked to other sectoral planning (e.g. finance, education, labour, human rights, gender). HIV monitoring should be embedded in broader health information systems within health systems.

2. Donor approaches should support partnerships, rather than undermine, the importance of integrated planning and program management, while governance structures should be strengthened and adapted to support integration. 
Human resources for health will need to be analyzed to insure the right distribution of skills to deliver integrated healthcare within health systems.

3. HIV services should be integrated with health and other services where appropriate. Quality of service delivery should be closely monitored and improved where necessary.

Country-specific governance experiences expands, capturing both positive and negative outcomes will be essential to provide clearer guidance and indicators for 'capacity building, partnerships, and advocacy' on how best to approach integration of HIV response within wider health, health systems, research development efforts, and most importantly by identifying stakeholders from government, NGOs, and private sector which constitute a key to successful outcomes.

By following a concerted policy of decentralization, and an action plan of linking NACP III within the scope of strengthening health systems through National Health Mission and National AIDS Control Program in India, hopes to control the epidemic and slow down its spread in general population within the shortest possible time is possible. The challenge is to sustain its effort by linking with stronger health systems' in reaching out to PLHA involving community-based innovations, NGOs, and using information communication technology to access to information, services, and insuring accountability at grassroots.

\section{Ethical issues}

Not applicable.

\section{Competing interests}

The author declares that he has no competing interests.

Author's contribution

$\mathrm{Mk}$ is the single author of the manuscript.

References

1. UNAIDS Report on the global AIDS epidemic [internet]. 2012. [cited 2013 October 15]. Available from: http://www.unaids.org/ en/media/unaids/contentassets/documents/epidemiology/2013/ gr2013/UNAIDS Global Report 2013 en.pdf.

2. NACO. Annual Report 2011-12 [internet]. 2012. [cited 2013 October 15]. Available from: https://nacoonline.org/upload/Publication/ Annual\%20Report/NACO_AR_Eng\%202011-12.pdf

3. Centre for Disease Control. HIV Surveillance Supplemental
Report: Monitoring selected national HIV prevention and care objectives by using HIV surveillance data-United States and 6 U.S. dependent area; 17(No. 3, part A). 2012. [cited 2013 October 15]. Available from: http://www.cdc.gov/hiv/pdf/statistics_2010_ HIV Surveillance Report vol 17 no 3.pdf

4. UN General Assembly twenty sixth special session [internet]. 2001. [cited 2013 October 15]. Available from: http://www.un.org/ga/aids/ docs/aress262.pdf

5. Hogle JA, Green E, Nantulya V, Stoneburner R, Stover J. What Happened in Uganda? Declining HIV Prevalence, Behaviour Change and National Response [internet]. Available from: http:// www.popline.org/node/250072

6. UNDP. The Role of Human Rights in Response to HIV, TB and Malaria [internet]. 2013. Available from: http://www.undp.org/ content/undp/en/home/librarypage/hiv-aids/the-role-of-humanrightsin-responses-to-hiv--tuberculosis-and-m.html

7. UNAIDS. Sexual Health Education Does Lead to Safer Sexual Behaviour. UNAIDS Review [internet]. 1997. Available from: http:// www.popline.org/node/274869

8. Remme JH, Adam T, Becerra-Posada F, D'Arcangues C, Devlin $\mathrm{M}$, Gardner C, et al. Defining research to improve health systems. PLoS Med 2010; 7: e1001000.

9. Kelly K, Parker W, Gelb S. HIVIAIDS, Economics and Governance in South Africa: Key Issues in Understanding Response [internet]. 2002. Available from: http://www.jointcenter.org/sites/default/files/ upload/research/files/AIDS_paper.pdf

10. Kunaka C. HIVIAIDS, democracy and governance in Southern Africa. Unpublished paper, 2000.

11. Over AM. The macroeconomic impact of AIDS in Sub-Saharan Africa (World Bank Africa Technical Department, Population, Health and Nutrition Division. Technical Working Paper). Population and Human Resources Dept., World Bank; 1992.

12. Whiteside $A$. The threat of HIVIAIDS to democracy and governance [internet]. 1999. Available from: http://pdf.usaid.gov/pdf_docs/ PNADR215.pdf

13. UNDP. Global Commission on HIV and The Law, 2012.

14. Gillies P. Effectiveness of alliances and partnerships for health promotion. Health Promot Int 1998; 13: 99-120.

15. UNDP. Strategy Note: HIV, Health and Development 2012-13, 2012.

16. NACO. NACP IV Strategic Planning Document. 2013. Available from: http://naco.gov.in/upload/Finance/AAP\%202013-14/Rajasthan.pdf

17. United Nations. Implementation of the United Nations Millennium Declaration: Report of the Secretary-General [internet]. 27 August 2004. Available from: http://www.un.org/millenniumgoals/ sgreport2004.pdf?OpenElement

18. UNAIDS. Global Report; UNAIDS report on the Global AIDS epidemic [internet]. 2013. Available from: http://www.unaids.org/ en/media/unaids/contentassets/documents/epidemiology/2013/ gr2013/UNAIDS_Global_Report_2013_en.pdf

19. UNAIDS \& WHO. Epidemiological Fact Sheets on HIVIAIDS and Sexually Transmitted Infections [internet]. 2004. Available from: http://data.unaids.org/publications/fact-sheets01/india_en.pdf 